九州大学学術情報リポジトリ

Kyushu University Institutional Repository

Growth Rate of Mycelium of Shiitake, Lentinus edodes, in Relation to Water Potential of Medium

Ohga, Shoj i

University Forest, Faculty of Agriculture, Kyushu University

https://doi.org/10.5109/23908

出版情報 : 九州大学大学院農学研究院紀要. 34 (4)，pp.413-420，1990-03. Kyushu University バージョン：

権利関係 : 


\title{
Growth Rate of Mycelium of Shiitake, Lentinus edodes, in Relation to Water Potential of Medium
}

\author{
Shoji Ohga \\ University Forests, Faculty of Agriculture, \\ Kyushu University 46-11, Fukuoka 812, Japan \\ (Received October 27, 1989)
}

\begin{abstract}
The growth rate of mycelium of shiitake, Lentinus edodes (Berk.) Sing., as a function of the water potential $(\psi)$ of the medium, whether it be agar or liquid, is qualitatively similar to that observed for other fungi in that there is a stimulation of the growth rate as $\psi$ is decreased slightly but as $\psi$ is decreased further, there is an actual inhibition of the growth rate. A slight reduction in $\psi$ stimulated the mycelial growth of L. edodes, where a maximum growth rate occurred at $-0.5 \mathrm{MPa}$ and there was no growth at $-5.3 \mathrm{MPa}$ on a $\mathrm{KCl}$-adjusted agar medium. The $\psi$ of sawdust substrate cultivating shiitake mushroom, especially in terms of physiologically available water, may be more important than the fresh-weight moisture content expressed as a percentage of weight. And oxygen availability might be a factor in the mycelial growth.
\end{abstract}

\section{INTRODUCTION}

The influence of the water potential $(\psi)$ of substrates on fungal growth has received increasing attention in recent years (Dix, 1985 ; Eamus and Jennings, 1986 ; Kuthubutheen and Webster, 1986 ; Al-Hamdani and Cooke, 1987 ;Badham, 1989). It is widely known fhat adequate water is required for growth of mushrooms in nature and under cultivation.

The growth of some basidiocarps are correlated with high atmospheric humidity (Badham, 1985). Transpiration and growth of a mushroom were significantly correlated with the humidity of the air. Most research on the influence of humidity on mushroom growth has been conducted with commercially important species, that is ; on Agaricus bisporus (Edwards, 1978), on Pleurotus ostreatus (Zadraiil, 1978), and on Volvariella volvacea (Chang and Miles, 1989).

Although $L$. edodes is the second most important commercially cultivated mushroom in the world, there is little information on its water relationships (Badham, 1989). Growth of mycelium is correlated more significantly with substrate moisture content than atmospheric humidity. Wood-decaying basidiomycetes appear to be particularly sensitive to a decreased $\psi$ of the substrate (Boddy, 1983 ;Dowson et al., 1989).

Measurement of water in a substrate is usually performed under ovendrying methods, though water availability is unknown in a biological sense. Within sawdust substrate the availability of water to the mycelia is affected by two main forces, matric potential $\left(\psi_{\mathrm{m}}\right)$ and osmotic potential $\left(\psi_{\mathrm{s}}\right)$. $\psi_{\mathrm{m}}$ is a result of forces associated with the interfaces between air and the sawdust matrix, and $\psi_{\mathrm{s}}$ is a result of the presence of solutes within the water. The sum of $\phi_{\mathrm{m}}$ and $\psi_{\mathrm{s}}$ is termed $\phi$. 
The aim of this paper is to provide data on the effect of $\psi$ on the growth of $L$. edodes mycelium.

\section{MATERIALS AND METHODS}

\section{Organism and culture}

The strain, Lentinus edodes (Berk.) Sing., was isolated from the collection of the Institute for Fermentation Osaka (IFO 7123). It was grown in $90 \mathrm{~mm}$ Petri dishes filled with a potato-dextrose agar (PDA, Difco) medium. A $4 \mathrm{~mm}$ diam plug was used for inoculation. Cultures were incubated at $25^{\circ} \mathrm{C}$.

\section{General methods}

Agar plates

The $\psi$ of the PDA agar medium was adjusted to desired values by adding appropriate molal concentrations of sucrose, glycerol, $\mathrm{NaCl}, \mathrm{KCl}$, or a salt mixture comprised of $\mathrm{NaCl}, \mathrm{KCl}$, and $\mathrm{Na}_{2} \mathrm{SO}_{4}$ in a molal ratio of $5: 3: 2$ (Ioannou et al., 1977). Then $90 \mathrm{~mm}$ diam Petri dishes were filled to a depth of $5 \mathrm{~mm}$ with the adjusted media. Each dish was inoculated with a $4 \mathrm{~mm}$ diam plug from the mycelial front margin an active young colony growing on agar, used to maintain cultures.

\section{Liquid medium}

Studies on liquid media were performed on a medium consisting of $7 \mathrm{~g}$ malt extract, $1 \mathrm{~g}$ peptone, $0.5 \mathrm{~g}$ yeast extract, and $1 \mathrm{~L}$ distilled water (Koske and Tessier, 1986). Polyethylene glycol (PEG) 4000 of a large molecular weight was used to adjust $\psi$ of the liquid media such as in previous microbial studies (Mexal et al., 1975 ; Brownell and Schneider, 1985). Liquid media were prepared in $100 \mathrm{ml}$ Erlenmeyer flasks, each containing $20 \mathrm{ml}$ of medium.

\section{Sawdust media}

Wood powder was prepared from freshly cut beech, Fagus crenata Bl. with Wiley mill, and it was separated into several particle sizes using a sieve shaker. For example, sawdust grade 20-48 contains particle sizes between 20 mesh and 48 mesh of the U. S. standard sieve size.

For matric control of $\psi$, various amounts of distilled water were added to the dry sawdust medium. This medium was composed of $20 \mathrm{~g}$ (dry weight) of wood powder and $4 \mathrm{~g}$ of rice bran. Approximately $24 \mathrm{~g}$ (dry weight) of sawdust mix was filled and compressed into $90 \mathrm{~mm}$ Petri dishes and a cavity having the size of the inoculant plug was made in the center. One spawn plug, a small cylinder of wood colonized by mycelium of $L$. edodes, was inoculated into the cavity.

\section{Psychrometric techniques}

The $\phi$ of each medium was determined by thermocouple psychrometry using a Wescor HR-33T microvoltmeter coupled to a C-52SF sample chamber. All measurements were made in the dew point mode, after calibration with a series of $\mathrm{NaCl}$ solutions of known potentials.

To determine $\psi$ of the agar medium, disks having $4 \mathrm{~mm}$ diam and 2-3 $\mathrm{mm}$ thick 
were used for each sample and an equilibrium time of $30 \mathrm{sec}$ as well as a cooling of the thermocouple junction time of $15 \mathrm{sec}$ were given. The apparatus was calibrated using Whatman antibiotic assay filter disks which had been left to soak in solutions of $\mathrm{NaCl}$ of known molality, any excess solution being quickly drained off. Measurements of $\psi$ were made at $25^{\circ} \mathrm{C}$ and converted to values at $20^{\circ} \mathrm{C}$ using tables (Lang, 1967).

The sawdust samples of approximately $0.1 \mathrm{~g}$ were picked up from the medium and within $10 \mathrm{~min}$ sealed into the sample chamber to allow for equilibrium. The same method was also applied for agar. The moisture content of the sawdust medium was determined by oven-drying methods. About $1.0 \mathrm{~g}$ was weighed into a weighing bottle and left for $16 \mathrm{~h}$ at $105^{\circ} \mathrm{C}$, followed by reweighing after cooling in a desiccator.

\section{Growth measurement}

Colony radial growth on solid media, agar or sawdust, were determined by measuring colony diameters with a slide caliper. Due to deviations from absolute circularity, both the largest and smallest diameters of the colonies were measured, and the mean was taken. Mycelial biomass grown on a sawdust medium was qualitatively determined by measuring the surface whiteness of the medium (Ohga, 1989). As for liquid media, the mycelium was separated from the medium by filtration through a weighed glass extraction thimble, then it was washed and dried at $105^{\circ} \mathrm{C}$ for $16 \mathrm{~h}$ and then cooled in a desiccator; the thimble was then reweighed.

\section{RESULTS AND DISCUSSION}

\section{Growth of fungi at varying media with different $\psi$ Agar plates}

Figure 1 shows the significant correlation between $\psi$ and the growth of L.edodes mycelium. The rate of growth of mycelium coming from an agar block inoculum was tested as a function of $\phi$ of the agar. The basal medium, which has no solutes, has a $\psi$ of $-0.24 \mathrm{MPa}$. At $-0.5 \mathrm{MPa}$, however, the growth rate of the mycelium with different solutes is greater than without solutes. At values below $-0.5 \mathrm{MPa}$, the growth rate declines in all instances with decreasing $\psi$. It should be noted that maximum radial growth in agar adjusted with several solutes occurred at $\psi$ below that of the nonadjusted basal medium. Below $-0.5 \mathrm{MPa}$, the use of glycerol as a solute yielded much higher growth rates than other solutes. Generally growth with $\mathrm{KC1}$ tended to be higher than with mixed salts. $\mathrm{NaCl}$ as solute usually yielded the lowest curve and no growth occurred below -1.6 $\mathrm{MPa}$ whereas growth on other salts often continued until -5.3 $\mathrm{MPa}$.

\section{Liquid medium}

Figure 2 gives the dry weight of $L$. edodes mycelium after 14 days growth on media of different $\psi$ produced by varying the concentration of PEG 4000 in the medium. The pattern of growth is much like that on agar with greater growth as $\psi$ is decreased slightly below that of the control but a decrease of growth when $\psi$ is decreased still further, with little growth at $-2.1 \mathrm{MPa}$. The findings of this study are in general agreement with other recent studies of the effects of $\psi$ on the growth of natural litterand wood-decomposing basidiomycetes (Harrower and Nagy, 1979 ; Clarke et al., 


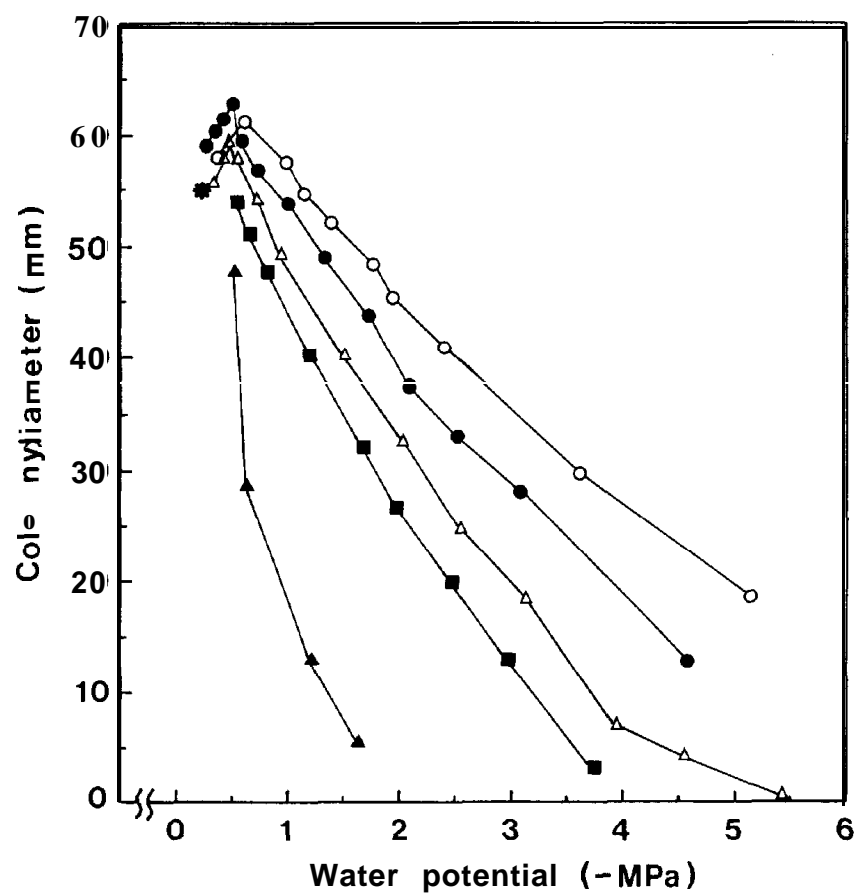

Fig. 1. Growth rate of mycelium from an agar plug inoculum of Lentinus edodes after 8 days over potato-dextrose agar medium of different water potential produced by following solutes : $\mathrm{O}:$ Glycerol, $\mathrm{O}$ : Sucrose, $\triangle: \mathrm{KCl}, \mathrm{A}: \mathrm{NaCl}$, $\quad$ : Salt mixture, * : agar containing none of these solutes.

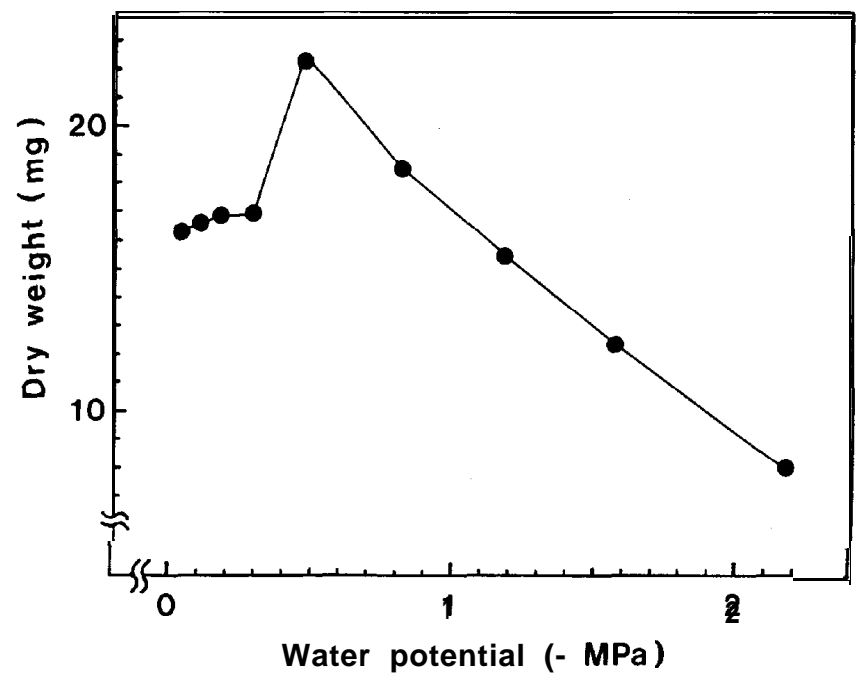

Fig. 2. Dry weight of mycelium of Lentinus edodes after 14 days on liquid media of different water potential produced by PEG 4000 . 
1980 ; Singh and Noah, 1989).

\section{Effects of moisture content and $\psi$ on mycelial growth in sawdust media}

When various amounts of water were added to the supplemented sawdust substrates the $\phi$ was not linearly related to percent moisture. Figure 3 gives results for colony diameter of $L$. edodes in relation to the initial moisture content of the substrates. The correlation is linear from $37 \%$ to $65 \%$ moisture. A marked increase of mycelial biomass was recognized on the substrate over $68 \%$ moisture, judging from surface whiteness of the medium.

\section{Effects of sawdust grain size on mycelial growth in sawdust media}

Differences in sawdust grain size will make many media with different $\phi$, especially in terms of physiologically available water, at the same moisture content when it is expressed as a percentage of weight (Fig. 4). Percentage of moisture always decreased during the course of the experiment, usually by $2-3 \%$. Within the range of these experiments, $\psi$ of the medium did not have a great influence on the transpiration rate.

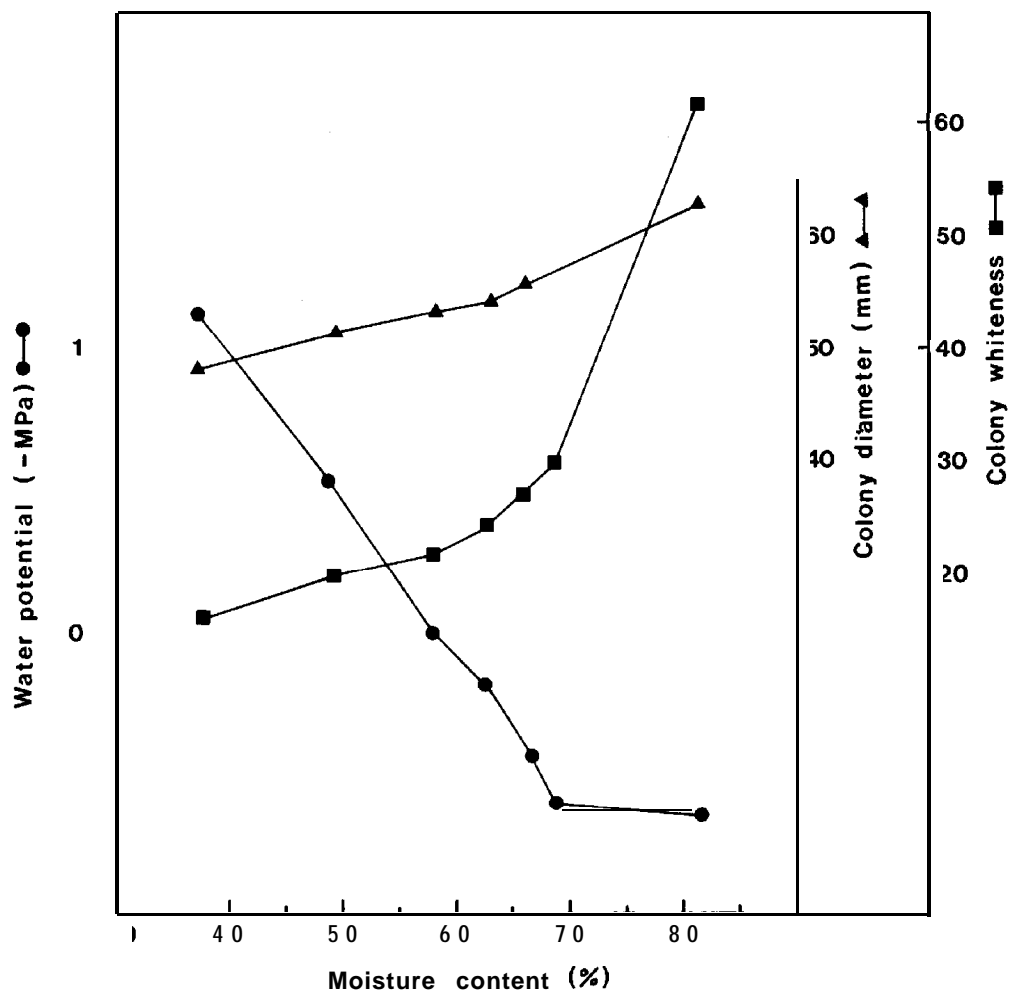

Fig. 3. Growth of Lentinus edodes mycelium and water potential on supplemented sawdust substrate at different moisture content (incubated for 11 days.).

: water potential, A : colony diameter, $\mathbf{\square}$ : colony whiteness 


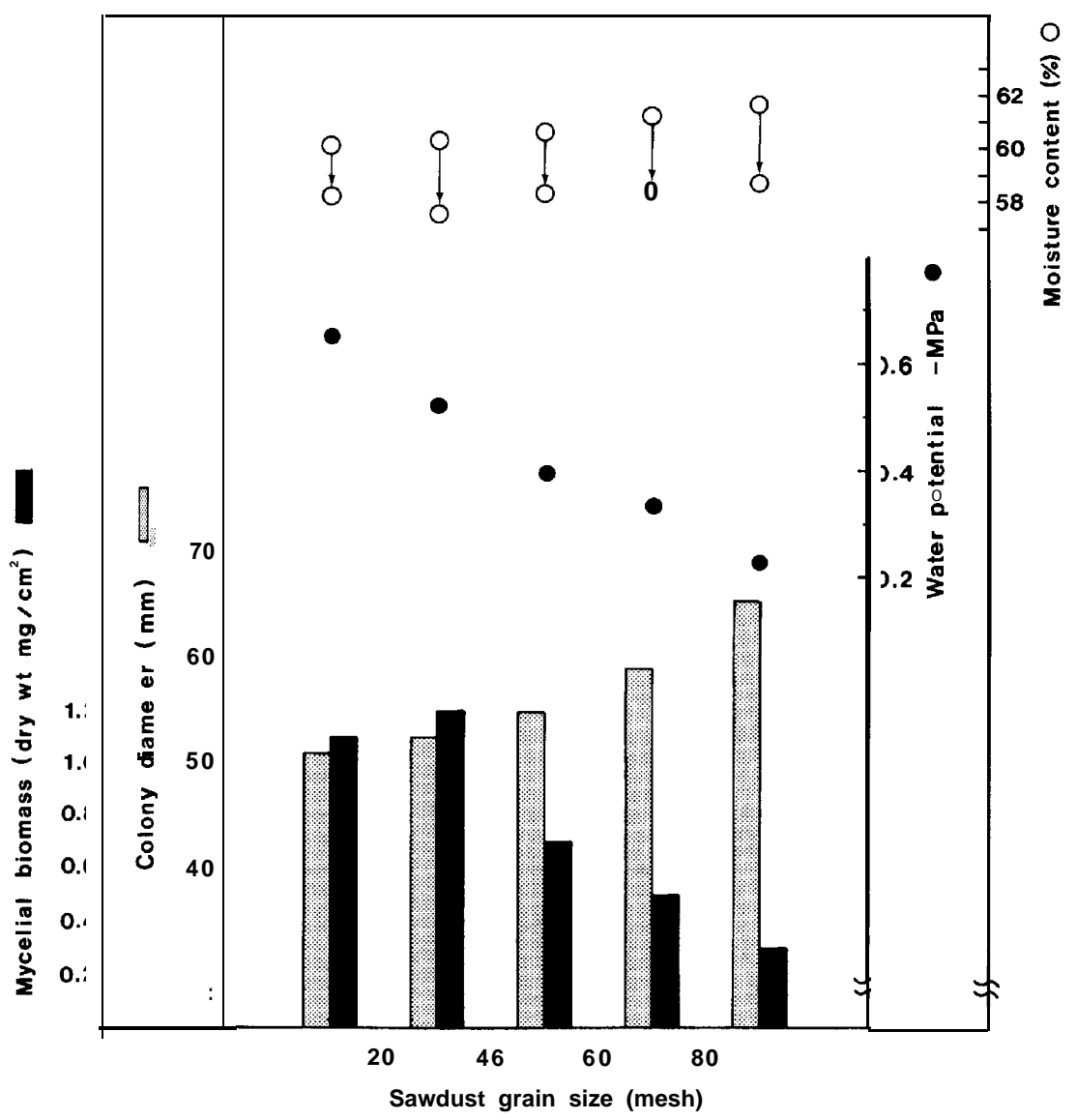

Fig. 4. Effect of sawdust grain size on mycelial development of Lentinusedodes and water potential of sawdust medium (incubated for 10 days.).

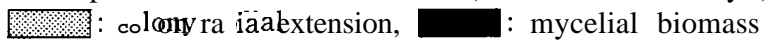

The symbols $\bigcirc \rightarrow \bigcirc$ show decrease percentage of moisture content.

Rapid colony radial extension of $L$. edodes mycelia on the medium surface area was expected having sufficient free water with increasing $\psi$. But great mycelial biomass did not increase in the inner parts of these sawdust medium with decreased $\psi$ (Fig. 4). This lower mycerial biomass might be due to the depletion of oxygen $(0$, around that part of the mycelium in the medium which is submerged. The diffusion rate of 0 , through water is much lower than through gas. Inadequate gas exchange, resulting in depletion of 0 , and increase in carbon dioxide concentrations, probably was the primary cause of the inhibition observed in saturated and very wet substrate.

When the $\psi$ of sawdust is decreased, the matrix force binds water to the medium particles even more strongly. In nature, this factor exerts the major effect of water availability to wood decaying fungi. It is important to note that $L$. edodes mycelium is more tolerant of water stress than other fungi and there is a stimulation effect to the 
mycelial growth as $\psi$ is decreased slightly whether the medium be agar, liquid or sawdust (as shown in Figs 1, '2 and 4).

According to the results of these experiments, L. edodes mycelium is capable of significant growth at substantial water deficiencies. Also, peak mycelial biomass is expected with a moisture content of a medium at about $60 \%$ and a decreased $\phi$ of $-0.5 \mathrm{MPa}$. Also, crude grain sawdust is suitable for adequate 0 , supply.

\section{ACKNOWLEDGEMENTS}

The author is grateful to Professor Emeritus T. Kondo of Kyushu University for constructive suggestions and advice, to Professor H. Imamura, Department of Forest Products, Kyushu University, for critical review of the munuscript, to Associate Professor K. Kira, University Forests, Kyushu University, for encouragement during the experiments.

And author would like to thank Mr Y. Jitsufuchi, Kyushu Electric Power Company Research Laboratory, for excellent technical suggestion and fruitful discussion.

\section{REFERENCES}

Al-Hamdani, A. M. and R. C. Cooke 1987 Effect of water potential on accumulation and exudation of carbohydrates and glycerol during sclerotium formation and myceliogenic germination in Sclerotinia sclerotionum. Trans. By. mycol. Soc., 89: 51-60

Badham, E. R. 1985 The influence of humidity upon transpiration and growth in Psilocybe cubensis. Mycologia, 77 : 932-939

Badham, E. R. 1989 Influence of water potential on growth of shiitake mycelium. Mycologia, 81: 464-468

Boddy, L. 1983 ,Effect of temperature and water potential on growth rate of wood-rotting basidiomycetes. Trans. By. mycol. Soc., 80: 141-149

Brownell, K. H. and R. W. Schneider 1985 Roles of matric and osmotic components of water potential and their interaction with temperature in the growth of Fusarium oxysporum in synthetic media and soil. Phytopathology, $75: 53-57$

Chang, S. T. and P. G. Miles 1989 Edible M ushroom and. Their Cultivation. CRC Press, Inc., Florida (United States), pp. 225-253

Clarke, R. W., D. H. Jennings and C. R. Coggins 1980 Growth of Serpula lacrimans in relation to water potential of substrate. Trans. By. mycol. Soc.,75:271-280

Dix, N. J. 1985 Changes in relationship between water content and water potential after decay and its significance for fungal successions. Trans. By. mycol. Soc., 85: 649-653

Dowson, C. G., L. Boddy and A. D. M. Rayner 1989 Development and extension of mycelial cords in soil at different temperatures and moisture contents. Mycol.Res., 92: 383-391

Eamus, D. and D. H. Jennings 1986 Tugor and fungal growth : Studies on water relations of mycelia of Serpula lacrimans and Phallus impudicus. Trans. By. mycol. Soc., $86:$ 527-535

Edwards, R. L. 1978 Cultivation in western countries : growing in houses. In "Biology and Cultivation of Edible Mushrooms" by S. T. Chang and W. A. Hayes, Academic Press, Inc., New York, pp. 299-336

Harrower, K. M. and L. A. Nagy 1979 Effects of nutrients and water stress on growth and sporulation of coprophilous fungi. Trans. By. mycol. Soc., 72: 459-462

Ioannou, N., R. W. Schneider, R. G. Grogan and J. M. Duniway 1977 Effect of water potential and temperature on growth, sporulation, and production of microsclerotia by Verticillium dahliae. Phytopathology, 67 : 637-644 
Koske, R. E. and B. Tessier 1986 Growth of some wood and litter decay basidiomycetes at reduced water potential. Trans. BY. mycol. Soc., 86: 156-158

Kuthubutheen, A. J. and J. Webster 1986 Effects of water availability on germination, growth and sporulation on coprophilous fungi. Trans. BY. mycol. Soc., $86: 77-91$

Lang, A. R. G. 1967 Osmotic coefficients and water potentials of sodium chloride solutions from 0 to $40^{\circ} \mathrm{C}$. Aust. J. Chem., $20: 2017-2023$

Mexal, J., J. T. Fisher, J. Osteryoung and C. P. P. Reid 1975 Oxygen availability in polyethylene glycol solutions and its implications in plant-water relations. Plant Physiol., $55: 20-24$

Ohga, S. 1989 The effects of administration of growth activating substances on the cultivation of shiitake mushroom, Lentinus edodes. Bull. Kyushu Univ. For., 61: 1-90 (in Japanese with English summary)

Singh, N. and A. N. D. Noah 1989 Effect of temperature and water potential on growth of Collybia sierraleonis. Mycol. Res., $92: 235-237$

Zadraiil, F. 1978 Cultivation of Pleurotus. In "Biology and Cultivation of Edible Mushrooms" by S. T. Chang and W. A. Hayes, Academic Press, Inc., New York, pp. 521-557 